\title{
THE MULTICRITERIA SELECTION METHODOLOGY OF THE DECISION SUPPORT SYSTEM
}

\author{
Justyna PATALAS-MALISZEWSKA*, Tadeusz KRUPA** \\ Faculty of Mechanical Engineering \\ University of Zielona Góra, 65-417 Zielona Góra, Poland \\ email: j.patalas@iizp.uz.zgora.pl \\ Faculty of Management \\ Warsaw University of Technology, 02-524 Warszawa, Poland \\ email: t.krupa@wz.pw.edu.pl
}

\begin{abstract}
An issue of building a tool orientated to the support of selection process of decision support system (DSS) for the sector of small and medium enterprises is presented in the article. A group method of data handling (GMDH) whose application allows to objectives a search process of required DSS, with assumed costs and other existing resource limitations, is proposed for this purpose. The article is devoted to a problem of GMDH adjustment to solving the tasks related to the selection of a required system from among the information systems of DSS class, according to the criteria determined by a future user of this system. The GMDH takes into account among other things such assumptions as: a precise description of dependences between input and output data in a specified time horizon, independence of the user's knowledge (the values of observed data from the past registered in the base are the input data) and minimization of modelling errors (the selection of solutions takes place by means of a selected evaluation rule of quality estimation).
\end{abstract}

Keywords: Decision support system (DSS), multi-criteria decision making model, group method of data handling (GMDH), information system of GMDH class, neuronal networks, genetic algorithms, root mean squared error of approximation, Iwachnienko polynomial, polynomial decision making model, SME sector.

\section{$1 \quad$ Introduction}

The decision support systems (DSS) are based on making use of various analytic, logic, statistic and heuristic optimization models and methods. A field of DSS applications includes a wide spectrum of decision making problems which exist in the surroundings. In other words, only technical conditions and a scope (accessibility) of the knowledge on a subject of specified fragment of reality determine a possibility of building a selection support system, dedicated to specified applications, and implementing an appropriate DSS.

A decision related to the DSS selection and implementation is usually based on a forecast of potential benefits resulting from its use in an enterprise [7]. However, a definite market niche for the tools oriented to the support of DSS selection and implementation process, useful in the conditions of a given enterprise, can be noticed here.

The problem boils down to finding a tool oriented to the support of DSS selection process for the enterprise. Building a multi-criteria decision making model, using a GMDH, means a possibility of objectivising a search process of appropriate DSS, with assumed costs and other existing resource limitations. A theoretical and apparatus background prepared in the form of information system which includes an operation methodology and utility program packet intended for carrying out simulation experiments in a preparation and selection process of optimum variant of decision plays an essential role in the DSS selection and its later application.

A GMDH (Group Method of Data Handling) can be applied to the selection of information system of DSS class on condition of appropriate adjustment of the system of this universal method to the specificity of DSS and their concrete applications.

In the article the GMDH (see point 2) is described in detail and it is shown that it can be a tool for building a multi-criteria model of DSS information system selection for the enterprise indeed. A polynomial decision making model of DSS selection which includes characteristics of these systems applied in the enterprise is prepared. A description of the model is included in point 3., however, point 4. covers a description of procedure related to the determination of polynomial decision making model of DSS selection. Directions of further researches are presented in the summary. 


\section{Group method of data handling (GMDH) as modelling algorithm}

There is a need of joint optimization of many parameters in decision making processes met in practice. Against a background of the data described in the references and having a practical application, the most often applied data of decision modelling and preparation tools include: artificial neuronal networks, decision making trees and rules and genetic algorithms.

The artificial neuronal networks are used first of all to detect characteristic features of input data, detect concentrations of input data and data compression. These networks are also used as a diagnostic tool because they do not require to be supervised when training. However, a collection of unique training data is often very difficult or it is simply impossible and then it is necessary to select a neuronal classifier based on the networks without supervision. The networks without supervision are submitted to the competitive training. The complete information on a presented input image is sent to each of processing elements of the network. Only this processing element whose vector of weights is similar to the most degree to the input vector is subject to the activation.

Standardized training vectors are applied to the networks' training. Training takes place according to a modified Grossberg-Kohonen rule and belongs to a variety of WTA (Winner Takes All). The modification lies in the fact that the activation of weights in every training step relates not only to a winning neuron but to all neurons being neighbours with it as well. At the start of training, all weights assume random and small values. An input vector activates a competition of the neurons. The winner updates its weights and allows the neurons from the neighbourhood to update the weights $[10,6]$.

The decision making trees and rules find an application when dividing a set of objects into subsets in such a way until their homogeneity with regard to the affinity to the classes is achieved. It is built a tree whose a hierarchic structure represents a decision making process in order to execute divisions of the set on the basis of variability scope of statistic features describing the objects (explained, dependent, forecast variables, variables describing the affinity). If a variable is of quantitative character then it is build a tree to explain a variable forming process (regressive tree). If a variable is of qualitative character then it is created a classification tree (a tree representing a division process of a set of objects into homogeneous classes. Its internal nodes describe a way of execution of this division - on the basis of values of the objects' features, and the leaves of the tree correspond with the classes to which the objects belong. And the edges of the tree represent the values of features on the basis of which a division is executed) [4].

The genetic algorithms (GA) enable to search for solutions in parallel in many points of decision making space. There is a possibility of simultaneous identification of many local optima in a set-handling process or ordered images of data by means of genetic algorithms. The genetic algorithms conduct searches, coming not from a single point but from a certain population, use the selection rules probabilistically and not deterministically [2]. The genetic algorithms require to code a set of parameters of the optimization task in the form of finite character string known as a genetic chain. The selection of solution is based on the random rules of crossing, mutation and multiplication and on the functions evaluating an adjustment process of population elements, for example, on the basis of minimization of squared deviation error.

The group method of data handling (GMDH) is an example of solution within the scope of inductive methods ${ }^{1}$. It takes into account among other things such assumptions as:

- A precise description of dependences between input and output data in a specified time horizon (random association),

A typology of connections is determined by means of evaluation criterion of quality estimation ${ }^{2}$, however, its training lies in the calculations of weights of connections by means of least squares method ${ }^{3}$ :

- Independence of theoretic knowledge (the values of observed data from the past registered in the base are the input data).

\footnotetext{
${ }^{1}$ Inductive methods - reasoning on the basis of empirical data [Farlow S.J. (Ed.), 1984].

${ }^{2}$ Estimation - assessment of the value of given parameter with a specified level of trust [Tadeusiewicz R., 1993].

${ }^{3}$ Least Squares Method - a result of next measure $y_{j}$ can be presented as a sum of (unknown) value measured $x$ and measure error $\varepsilon_{j}, \boldsymbol{y}_{j}=\boldsymbol{x}+\varepsilon_{j}$. From the value $\varepsilon_{j}$ we expect so that a sum of squares is as least as possible [Farlow S.J.,1984]:

$\sum \varepsilon_{j}^{2}=\sum_{j}\left(x-y_{j}\right)^{2}=\min$
} 
Table 1. The financial parameters of SME sector enterprise (source: self study)

\begin{tabular}{|c|c|c|c|}
\hline $\begin{array}{c}\text { Period (the data from financial } \\
\text { documentation on) }\end{array}$ & Income & Sales & Payables \\
\hline 30.06 .2005 & 340 thousand & 280 thousand & 2900 thousand \\
\hline 31.12 .2006 & 383 thousand & 313 thousand & 3145 thousand \\
\hline 30.06 .2007 & 580 thousand & 476 thousand & 2100 thousand \\
\hline 31.10 .2008 & 620 thousand & 520 thousand & 2500 thousand \\
\hline
\end{tabular}

In a general case, all points being in the data space are a subject matter of the consideration. However, it is beneficial to limit a domain to a subset of observations not including redundant information.

- Minimization of modelling errors (the selection of the most approximating polynomials takes place by means of a selected evaluation rule of quality estimation).

It is of importance to select a concrete formula of external criterion. One of them is a criterion of regularity defined as a root mean squared error of approximation calculated for the data not used to determine the values of parameters of partial model (see (6), [5]).

Let's consider an example illustrating an application of GMDH.

A structural identification of decision making model of information system selection for the enterprise A by means of GMDH allows to estimate economical effects of implementation of this system. For this purpose the characteristics of financial parameters of the enterprise within a 2-year period (covering a pre-implementation period as well as a period after the implementation of information system in the enterprise - see Table 1) are audited.

Assuming that a model representing an initial variable of the object (enabling to evaluate a level of implementation effectiveness of information system with respect to finance) is searched for, the following functional dependence can be postulated:

$$
\mathrm{Y}=\mathrm{f}\left(\mathrm{X}_{1}, \mathrm{X}_{2}\right)+\mathrm{e}
$$

where:

$\mathrm{Y}$ - income value in the enterprise,

$\mathrm{x}_{1}$ - sales value in the enterprise on 30.06.2005, 31.12.2006, 30.06.2007, 31.10.2008,

$\mathrm{x}_{2}$ - payables value in the enterprise on 30.06 .2005 , 31.12.2006, 30.06.2007, 31.10.2008, e - error caused by existence of inaccessible disturbances in terms of measurements, it is an independent random variable, where $\mathrm{E}(\mathrm{e})=0$ and $\operatorname{Var}(\mathrm{e})=\delta^{2}<\infty$, therefore this value is omitted in further calculations.

A designation of the object's structure by means of GMDH algorithm lies in an iterative (step) repetition of determined sequence of operations leading to an evolutionary resultant structure ${ }^{4}$. This process is finished when the value $r_{j}^{2}$ stops decreasing (optimum degree of polynomial complexity is achieved).

In order to determine a population of polynomials (4) for the object with $\mathrm{m}$ inputs $\mathrm{x}_{1}, \mathrm{x}_{2}, \ldots \mathrm{x}_{\mathrm{m}}$ and one output $\mathrm{y}$ it is created a matrix of the following form:

$$
X=\left[\begin{array}{l}
x_{11}, x_{12}, \ldots x_{1 m} \\
x_{21}, x_{22}, \ldots x_{2 m} \\
\cdots \\
x_{t 1}, x_{t 2}, \ldots x_{t m} \\
\cdots \\
x_{n 1}, x_{n 2}, \ldots x_{n m}
\end{array}\right]
$$

in which the columns $1 \ldots \mathrm{m}$ represent independent variables $\mathrm{x}_{1}, \mathrm{x}_{2}, \ldots \mathrm{x}_{\mathrm{m}}$.

In the case under consideration we receive:

$$
\mathrm{X}=\left[\begin{array}{lll}
1, & 280, & 2900 \\
1, & 313, & 3145 \\
1, & 476, & 2100 \\
1, & 520, & 2500
\end{array}\right]
$$

and a vector $y$ of output values:

$$
\begin{aligned}
& y=\left[y_{1}, y_{2}, \ldots y_{t}, \ldots y_{n}\right]^{T} \\
& y=[340,383,580,620]^{T}
\end{aligned}
$$

It is assumed that the matrix columns $\mathrm{X}$ are linearly independent.

\footnotetext{
${ }^{4}$ Evolutionary resultant structure - a set of parameters of a given object, algorithmic equivalent of genotype (set of genes of a given individual) [Goldberg D.E., 1995].
} 
Table 2. The test data for the partials models (source: self study)

\begin{tabular}{|c|c|c|c|}
\hline $\begin{array}{c}\text { Period (the data from financial } \\
\text { documentation on) }\end{array}$ & Income & Sales & Payables \\
\hline 31.12 .2008 & 630 thousand & 580 thousand & 2500 thousand \\
\hline 30.06 .2009 & 620 thousand & 560 thousand & 2700 thousand \\
\hline 31.12 .2009 & 600 thousand & 520 thousand & 2700 thousand \\
\hline
\end{tabular}

The input data are divided into training data and test data in this way that:

$$
\left[\begin{array}{l}
\mathrm{y}_{1} \\
\mathrm{y}_{2} \\
\cdots \\
\mathrm{y}_{\mathrm{t}}
\end{array}\right]\left[\begin{array}{l}
\mathrm{x}_{11}, \mathrm{x}_{12}, \ldots \mathrm{x}_{1 \mathrm{~m}} \\
\mathrm{x}_{21}, \mathrm{x}_{22}, \ldots \mathrm{x}_{2 \mathrm{~m}} \\
\cdots \\
\mathrm{x}_{\mathrm{t} 1}, \mathrm{x}_{\mathrm{t} 2}, \ldots \mathrm{x}_{\mathrm{tm}}
\end{array}\right] \text { division line }
$$

A division line divides a matrix (3) into the training data $(1,2, \ldots \mathrm{t})$ and test data $(\mathrm{t}+1, \ldots \mathrm{n})$. The training data shall be used to construct a model of the object, however, the test data shall be used to evaluate the partial models. The data as the test data are assumed in table 2 .

$$
\begin{gathered}
\mathrm{Y} \\
{\left[\begin{array}{l}
630 \\
620 \\
600
\end{array}\right] \quad\left[\begin{array}{c}
1,580,2500 \\
1,560,2700 \\
1,520,2700
\end{array}\right]}
\end{gathered}
$$

In the first step, for each pair of independent variables $<x_{p}, x_{q}>, p=1,2, \ldots m-1, q=p+1, \ldots m$ it is created a approximating polynomial in a general form:

$$
\begin{aligned}
& \mathrm{y}^{*}=\mathrm{A}_{\mathrm{pq}}+\mathrm{B}_{\mathrm{pq}} \mathrm{x}_{\mathrm{p}}+\mathrm{C}_{\mathrm{pq}} \mathrm{x}_{\mathrm{q}}+\mathrm{D}_{\mathrm{pq}} \mathrm{x}_{\mathrm{p}}^{2} \\
& +\mathrm{E}_{\mathrm{pq}} \mathrm{x}_{\mathrm{q}}^{2}+\mathrm{F}_{\mathrm{pq}} \mathrm{x}_{\mathrm{p}} \mathrm{x}_{\mathrm{q}}
\end{aligned}
$$

known as a Iwachnienko’s polynomial.

The polynomial coefficients (4) are determined for training observations $t$ by means of least squares method, i.e. based on the condition:

$$
\mathrm{S}_{\mathrm{R}}=\sum_{\mathrm{i}=1}^{\mathrm{t}}\left(\mathrm{y}_{\mathrm{i}}-\mathrm{y}_{\mathrm{i}}^{*}\right)^{2}=\min
$$

where:

$$
\begin{aligned}
& y_{i}^{*}=A_{p q}+B_{p q} x_{i p}+C_{p q} x_{i q}+D_{p q} x_{i p}^{2} \\
& +E_{p q} x_{i q}^{2}+F_{p q} x_{i p} x_{i q}
\end{aligned}
$$

It is jointly created $\mathrm{m}(\mathrm{m}-1)$ of polynomials. Every polynomial $y_{i}^{*}(6)$ is determined for all data of the matrix X. Calculated values are placed in separate columns of the auxiliary matrix $\mathrm{Z}$.

In the second step for every column $\mathrm{j}=1,2, \ldots \mathrm{m}(\mathrm{m}-1)$ of the matrix $\mathrm{Z}$ it is determined a regularity criterion based on the formula:

$$
r_{j}^{2}=\frac{\sum_{i=t+1}^{n}\left(y_{i}-z_{i j}\right)^{2}}{\sum_{i=t+1}^{n} y_{i}^{2}}
$$

where:

$\mathrm{i}$ - next observation of the matrix $\mathrm{X}$,

$\mathrm{j}=1,2, \ldots \mathrm{m}(\mathrm{m}-1)$ column number of the matrix $\mathrm{Z}$.

A received value of regularity criterion (see (7)) is an evaluation of quality of a given polynomial.

In the third step there is a selection of the best polynomials (of the least coefficient value $r_{j}$ ). On the assumption that the population of polynomials is weak, from the matrix $\mathrm{Z}$ there are selected $\mathrm{m}$ columns which are transferred to the matrix $X$. In this way the output data becomes the input data for the next generation. A minimal value of regularity criterion $r_{j}$ is determined. The coefficients' values of selected polynomials are retained.

This process is repeated till the values of regularity criterion (see (6)) decrease. When the process is completed, the best polynomial from among the polynomials of the previous generation is selected. A polynomial being a model of the object is a result of algorithm operation.

In the case under consideration, for the training data, the following values of regularity criterion are obtained:

$$
\begin{aligned}
& \mathrm{Rx}_{1}, \mathrm{x}_{2}=6,58 \\
& \mathrm{Rx}_{1}, \mathrm{x}_{3}=14,99 \\
& \mathrm{Rx}_{2}, \mathrm{x}_{3}=10,32
\end{aligned}
$$


In this way, as giving the least error of modelling, "the best" polynomial is selected depending on the enterprise's income (y), for the training data:

$$
\begin{aligned}
\mathrm{y}= & \mathrm{F}\left(\mathrm{x}_{1}, \mathrm{x}_{2}\right)=-8271,81-1,97 \mathrm{x}_{1}+11,14 \mathrm{x}_{2} \\
& +0,02 \mathrm{x}_{1}{ }^{2}+0,002 \mathrm{x}_{2}{ }^{2}+0,0002 \mathrm{x}_{1} \mathrm{x}_{2}
\end{aligned}
$$

where:

$\mathrm{F}\left(\mathrm{x}_{1}, \mathrm{x}_{2}\right)$ - income of SME sector enterprise,

$\mathrm{x}_{1}-1$,

$\mathrm{x}_{2}-$ sales in the enterprise.

The value $F\left(x_{1}, x_{2}\right)$ is a forecast value of income for the enterprise depending on a current value $\mathrm{x}_{2}$.

The following values of regularity criterion are obtained for the test data:

$$
\begin{aligned}
& \mathrm{Rx}_{1}, \mathrm{x}_{2}=0,7 \\
& \mathrm{Rx}_{1}, \mathrm{x}_{3}=12,64 \\
& \mathrm{Rx}_{2} \mathrm{x}_{3}=1,1
\end{aligned}
$$

In this way, as giving the least error of modelling, "the best" polynomial $\mathrm{y}=\mathrm{F}\left(\mathrm{x}_{1}, \mathrm{x}_{2}\right)$ is selected depending on the enterprise's income (y). The operations on the test data confirmed a selection correctness of "the best" polynomial for the training data. The presented considerations related to the GMDH allow to specify individual stages of the design of polynomial decision making model of DSS information system selection for the enterprise.

\section{Polynomial decision making model of decision support system selection}

The design of decision making model of decision support system selection starts with the collection of information on an investigated object. There can be the data coming from the experts or there can be the empirical data obtained as a result of the object functioning observation [8].

The model identification includes:

- determination of characteristics (functionalities) of given information system used in a given enterprise,

- determination of functioning indexes in a given functional department of the enterprise on the basis of measurement in an investigated object (enterprise),

- control of forecast quality of the values of arbitrarily selected functioning indexes by means of selected model on the basis of comparison of forecast values of the indexes with the real values of these indexes in the enterprise.
For the purpose of the determination of the model it is assumed that:

- the base of functioning indexes of the sales department in the SME and information system parameters (system functionalities) (see Table 3 and Table 4) constitutes a base of building of the model,

- the values of input parameters (information system parameters, values of functioning indexes of a given department in the enterprise) and output parameter (value of profit in the enterprise or value of enterprise effectiveness index) should not change within a radically short period of time.

\subsection{Design methodology of polynomial decision making model of DSS selection}

\section{Stage 1 Identification}

A GMDH multi-level algorithm enables to make a synthesis of the model for selected characteristics of given DSS information system (i.e. functionalities of this DSS) with arbitrarily selected indexed of a given department of the enterprise. Both mentioned elements of the algorithm are determined by the designer. Therefore, the modelling must be preceded by an identification phase of the model's element.

In this phase the investigations in the SME sector enterprise (see Table 3) related to the functionalities of implemented information solution on the basis of an example of sales department are carried out. A closed set of business processes ${ }^{5}$ supported by an information tool implemented in the enterprise and a set of values of functioning indexes of the sales department (see Table 4) are obtained. It is assumed that a model of DSS information system selection of the enterprise is in the form of second-degree polynomial of two variables. A selection of partial polynomials is made by means of regularity criterion (7).

The value base of information system parameters (functionalities, see Table 3) constitutes a set of characteristics (functionalities) of information system in a given enterprise. The bases of functioning indexes of a given department in the enterprise, parameters of information system and output values (see Table 3, Table 4 and Table 5) cane be freely built by the designer.

\footnotetext{
${ }^{5}$ Business processes - a set of mutually connected functions, limited by the rules, in order to achieve a set of economic objectives appropriate for a given enterprise within a specified time limit, [Shang S., Seddon P., 2000].
} 
Table3. The value base of information system parameters in the SME (system functionalities) for the sales department (value 1: the task is realized by the system, value 0 : the task is not realized by the system)

(source: self study)

\begin{tabular}{|c|c|}
\hline Functionality of information system in SME & $\begin{array}{l}\text { Value of } \\
\text { task real- } \\
\text { ized } \\
\text { by system } \\
\end{array}$ \\
\hline $\mathrm{x}_{1}$ : Search for contacts & 1 \\
\hline $\mathrm{x}_{2}:$ Qualification of potential customers & 0 \\
\hline $\mathrm{x}_{3}$ : Analysis of market penetration possibilities and degree & 0 \\
\hline $\mathrm{x}_{4}$ : Determination of target markets & 0 \\
\hline $\mathrm{x}_{5}$ : Investigation of the customer's situation and needs & 0 \\
\hline $\mathrm{x}_{6}$ : Preparation of a map of the customer's decision making process and his important factors & 1 \\
\hline $\mathrm{x}_{7}$ : Development of sales conditions & 0 \\
\hline $\mathrm{x}_{8}$ : Determination of organizational persons impacting on purchase decisions & 1 \\
\hline $\mathrm{x}_{9}$ : Determination of a kind of contacts with the customer & 1 \\
\hline $\mathrm{x}_{10}$ : Search for and determination of potential customers & 0 \\
\hline $\mathrm{x}_{11}$ : Delivery of information on the company's products and services to the customer & 0 \\
\hline $\mathrm{x}_{12}$ : Order of advertisements in media & 0 \\
\hline $\mathrm{x}_{13}$ : Development of layout and graphic form of advertisements in media & 1 \\
\hline $\mathrm{x}_{14}$ : Direct talks with the customer at the seat of the company & 0 \\
\hline $\mathrm{x}_{15}:$ Direct talks with the customer at the seat of the customer & 0 \\
\hline $\mathrm{x}_{16}:$ Phone talks with the customer & 0 \\
\hline $\mathrm{x}_{17}$ : Development of product/service presentation and offer & 1 \\
\hline $\mathrm{x}_{18}$ : Trips to the customer & 0 \\
\hline $\mathrm{x}_{19}$ : Information on the product's properties & 1 \\
\hline $\mathrm{x}_{20}$ : Comparison of the company's offer with competitive offers & 1 \\
\hline $\mathrm{x}_{21}$ : Cooperation when solving the customer's problems & 0 \\
\hline $\mathrm{x}_{22}$ : Persuasion, negotiation and determination of sales conditions & 0 \\
\hline $\mathrm{x}_{23}$ : Formulation of proposals in writing and preparation of documentation & 1 \\
\hline $\mathrm{x}_{24}$ : Submission of final offer & 0 \\
\hline $\mathrm{x}_{25}$ : Conclusion of transaction & 1 \\
\hline $\mathrm{x}_{26}$ : Preparation of orders and supplementary orders & 1 \\
\hline $\mathrm{x}_{27}$ : Register of order to the deliverer & 1 \\
\hline $\mathrm{x}_{28}$ : Register of purchase & 1 \\
\hline $\mathrm{x}_{29}$ : Register of article sales and hand-over & 1 \\
\hline $\mathrm{x}_{30}$ : Invoicing & 1 \\
\hline $\mathrm{x}_{31}$ : Register of value returns and corrections to trade documents & 1 \\
\hline $\mathrm{x}_{32}$ : Solving problems related to crediting, invoicing, execution of receivables & 1 \\
\hline $\mathrm{x}_{33}$ : Complaints and collection of articles from the customer & 1 \\
\hline $\mathrm{x}_{34}$ : Inventory, control of warehouse balances & 1 \\
\hline $\mathrm{x}_{35}$ : Monitoring of warehouse balances & 1 \\
\hline $\mathrm{x}_{36}$ : Development of marketing programs & 1 \\
\hline $\mathrm{x}_{37}$ : Execution of market analyses for the needs of the customer & 1 \\
\hline $\mathrm{x}_{38}$ : Presentation of new products and technologies & 0 \\
\hline $\mathrm{x}_{39}$ : Solving problems related to production & 0 \\
\hline $\mathrm{x}_{40}:$ Participation in meetings & 0 \\
\hline $\mathrm{x}_{41}$ : Administration work & 1 \\
\hline
\end{tabular}




\begin{tabular}{|l|c|}
\hline $\mathrm{x}_{42}:$ Participation in trainings & 0 \\
\hline $\mathrm{x}_{43}:$ Supervision over sales plan & 1 \\
\hline $\mathrm{x}_{44}:$ Handling of complaints - quantitative and value & 1 \\
\hline $\mathrm{x}_{45}:$ Collection of data in the data base of the customers, potential customers, markets, etc. & 1 \\
\hline $\mathrm{x}_{46}:$ Notification of dispatch & 0 \\
\hline $\mathrm{x}_{47}:$ Sales forecasts & 1 \\
\hline $\mathrm{x}_{48}:$ Segmentation of the customers & 1 \\
\hline $\mathrm{x}_{49}:$ Contact centre with the customers & 1 \\
\hline $\mathrm{x}_{50}:$ Auction of the deliverers & 1 \\
\hline $\mathrm{x}_{51}:$ Settlement of the sales representatives & 1 \\
\hline $\mathrm{x}_{52}:$ Planning of routes of the sales representatives & 1 \\
\hline $\mathrm{x}_{53}:$ Planning of types and elements of visits of the sales representatives & 1 \\
\hline $\mathrm{x}_{54}:$ Creation of tasks of the sales representatives & 1 \\
\hline $\mathrm{x}_{55}:$ Reporting own articles and presence of the competition's article at the customer's & 1 \\
\hline $\mathrm{x}_{56}:$ Creation of sales plans for sales regions & 1 \\
\hline
\end{tabular}

Table 4. Selected functionality indexes of sales department in the enterprise (source: self study)

\begin{tabular}{|c|c|c|c|}
\hline \multirow{2}{*}{ Functionality indexes of sales department } & \multicolumn{3}{|c|}{ Value } \\
\hline & 2007 & 2008 & 2009 \\
\hline $\begin{array}{l}\mathrm{x}_{1}: \text { Share of orders realized on time } \\
\text { (number of orders realized in at a requested time / } \\
\text { number of received orders } \mathrm{x} 100 \% \text { ) }\end{array}$ & 0,84 & 0,91 & 0,96 \\
\hline $\begin{array}{l}\mathrm{x}_{2}: \text { Share of advertised deliveries } \\
\text { (number of advertised deliveries / total number of deliveries }\end{array}$ & 0,06 & 0,07 & 0,57 \\
\hline $\begin{array}{l}\mathrm{x}_{3}: \text { Profitability of assets } \\
\text { (profit/assets) }\end{array}$ & 0,14 & 0,13 & 0,13 \\
\hline $\begin{array}{l}\mathrm{x}_{4}: \text { Rotation of reserves } \\
\text { (revenue / reserves) }\end{array}$ & 7,17 & 6,75 & 6,45 \\
\hline $\begin{array}{l}\mathrm{x}_{5} \text { : Profitability of equity } \\
\text { (profit/equity) }\end{array}$ & 0,32 & 0,30 & 0,35 \\
\hline $\begin{array}{l}\mathrm{x}_{6}: \text { Work productivity } \\
\text { (revenues from sales/value of work of the total employed) }\end{array}$ & 4,72 & 11,30 & 11,76 \\
\hline
\end{tabular}

Table 5 Values of output data: enterprise profit, enterprise effectiveness index (source: self study)

\begin{tabular}{|c|c|c|c|}
\hline \multirow{2}{*}{ Output data of decision making model } & \multicolumn{3}{|c|}{ Value } \\
\hline & 2007 & 2008 & 2009 \\
\hline $\begin{array}{l}\mathrm{y}_{1}: \text { Profit in the enterprise } \\
\text { (in thousand PLN) }\end{array}$ & 773 & 710 & 805 \\
\hline $\begin{array}{l}\mathrm{y}_{2}: \text { Enterprise effectiveness (receivables rotation index) } \\
\text { (revenues from sales /average revenues balance) }\end{array}$ & 8,54 & 10,3 & 10,69 \\
\hline
\end{tabular}

In the case under consideration we receive:

$$
X=\left[\begin{array}{cccccc}
0,84 & 0,06 & 0,14 & 7,17 & 0,32 & 4,72 \\
0,91 & 0,07 & 0,13 & 6,75 & 0,30 & 11,30 \\
0,96 & 0,57 & 0,13 & 6,45 & 0,35 & 11,76
\end{array}\right]
$$$$
\text { and } \mathrm{y}_{1}=\left[\begin{array}{l}
773 \\
710 \\
805
\end{array}\right] \text { or } \mathrm{y}_{2}=\left[\begin{array}{l}
8,54 \\
10,3 \\
10,69
\end{array}\right]
$$ 
Stage 2 Determination of family (population) of partial models

The design of a model in the GMDH algorithm is realized in a step-by-step manner. A family of regression polynomials is generated in every next step. Because it is determined that each of them is a function of two variables, these polynomials are created for all possible pairs of arguments.

The task of GMDH algorithm operation is to determine "the best" polynomial of the least regularity criterion value (see 2.VII) for the object (the enterprise of the sector). A process of GMDH algorithm evaluation is carried out on the basis of the data included in the base of SME functioning indexes and information system parameters (see Table 3, Table 4 and Table 5).

Stage 3 Selection of partial models

When the family of regression polynomials is generated, there is a selection of these ones from them which approximate an investigated dependence between the characteristics of given DSS information system (i.e. functionalities of this DSS) with arbitrarily selected indexes of given functional department of the enterprise the best (see Table 3, Table 4 and Table 5).

The least value of regularity criterion is found for every partial solution. The stages 2 and 3 are repeated till this value stops decreasing. It means that an optimal model is found. It is a model (polynomial of regression) for which a regularity criterion reached the least value. The following values of regularity criterion are received:

- for $\mathrm{y}_{1}$ :

$$
\begin{aligned}
& \mathrm{Rx}_{1}, \mathrm{x}_{2}=0,73 \\
& \mathrm{Rx}_{1}, \mathrm{x}_{3}=2,51 \mathrm{E}+0,9 \\
& \mathrm{Rx}_{1}, \mathrm{x}_{4}=1,99 \mathrm{E}+22 \\
& \mathrm{Rx}_{1}, \mathrm{x}_{5}=3,89 \mathrm{E}+09 \\
& \mathrm{Rx}_{1}, \mathrm{x}_{6}=5,11 \mathrm{E}+10 \\
& \mathrm{Rx}_{2}, \mathrm{x}_{3}=1,04 \mathrm{E}+10 \quad \\
& \mathrm{Rx}_{2}, \mathrm{x}_{4}=0,687365 \text { (the least value } \\
& \mathrm{Rx}_{2}, \mathrm{x}_{5}=8,79 \mathrm{E}+12 \quad \text { of regularity criterion) } \\
& \mathrm{Rx}_{2}, \mathrm{x}_{6}=1,45 \mathrm{E}+11 \\
& \mathrm{Rx}_{3}, \mathrm{x}_{4}=5,23 \mathrm{E}+10 \\
& \mathrm{Rx}_{3}, \mathrm{x}_{5}=0,71 \quad \\
& \mathrm{Rx}_{3}, \mathrm{x}_{6}=2,63 \mathrm{E}+10 \\
& \mathrm{Rx}_{4}, \mathrm{x}_{5}=2,27 \\
& \mathrm{Rx}_{4}, \mathrm{x}_{6}=2,32 \\
& \mathrm{Rx}_{5}, \mathrm{x}_{6}=0,95
\end{aligned}
$$

In this way, as giving the least error of modelling, "the best" polynomial is selected depending on the enterprise's profit $\left(\mathrm{y}_{1}\right)$ :

$$
\begin{aligned}
\mathrm{y}_{1}= & \mathrm{F}\left(\mathrm{x}_{2}, \mathrm{x}_{4}\right)=585,57+0,19 \mathrm{x}_{1}+0,22 \mathrm{x}_{3} \\
& -0,0005 \mathrm{x}_{1}{ }^{2}+0,0008 \mathrm{x}_{3}{ }^{2}+0,0005 \mathrm{x}_{1} \mathrm{x}_{3}
\end{aligned}
$$

where:

$\mathrm{F}\left(\mathrm{x}_{2}, \mathrm{x}_{4}\right)$ - profit of SME sector enterprise,

$\mathrm{x}_{1}$ - "share of advertised deliveries" index,

$\mathrm{x}_{3}$ - "assets / rotation of reserves" index.

The value $F\left(x_{2}, x_{4}\right)$ is a forecast profit value for the enterprise after the implementation of DSS (depending on a current values $\mathrm{x}_{2}$ and $\mathrm{x}_{4}$ ).

For the exemplary values $\mathrm{x}_{2}=0,02$ and $\mathrm{x}_{4}=6$, the profit value for the enterprise after the implementation of DSS should amount to:

$$
\begin{aligned}
& \mathrm{y}_{1}=\mathrm{F}\left(\mathrm{x}_{2}, \mathrm{x}_{4}\right)=586 \text { thousand, } \\
& \text { - for } \mathrm{y}_{2} \text { : }
\end{aligned}
$$

the following values of regularity criterion are received:

$$
\begin{aligned}
& \mathrm{Rx}_{1}, \mathrm{x}_{2}=0,83 \\
& \mathrm{Rx}_{1}, \mathrm{x}_{3}=0,30 \text { (the least value of regularity criterion) } \\
& \mathrm{Rx}_{1}, \mathrm{x}_{4}=0,60 \\
& \mathrm{Rx}_{1}, \mathrm{x}_{5}=2,4 \\
& \mathrm{Rx}_{1}, \mathrm{x}_{6}=1,43 \mathrm{E}+11 \\
& \mathrm{Rx}_{2}, \mathrm{x}_{3}=1,38 \mathrm{E}+10 \\
& \mathrm{Rx}_{2}, \mathrm{x}_{4}=0,7 \\
& \mathrm{Rx}_{2}, \mathrm{x}_{5}=1,92 \\
& \mathrm{Rx}_{2}, \mathrm{x}_{6}=0,37 \\
& \mathrm{Rx}_{3}, \mathrm{x}_{4}=5,4 \mathrm{E}+10 \\
& \mathrm{Rx}_{3}, \mathrm{x}_{5}=6,96 \mathrm{E}+10 \\
& \mathrm{Rx}_{3}, \mathrm{x}_{6}=1,81 \\
& \mathrm{Rx}_{4}, \mathrm{x}_{5}=2,05 \\
& \mathrm{Rx}_{4}, \mathrm{x}_{6}=1,14 \mathrm{E}+12 \\
& \mathrm{Rx}_{5}, \mathrm{x}_{6}=1,45 \mathrm{E}+11
\end{aligned}
$$

and "the best" polynomial is selected depending on the enterprise's effectiveness $\left(\mathrm{y}_{2}\right)$ :

$$
\begin{aligned}
\mathrm{y}_{2}= & \mathrm{F}\left(\mathrm{x}_{1}, \mathrm{x}_{3}\right)=48,46-6,11 \mathrm{x}_{1}-1,34 \mathrm{x}_{3}+0,52 \mathrm{x}_{1}{ }^{2} \\
& -0,07 \mathrm{x}_{3}{ }^{2}-0,11 \mathrm{x}_{1} \mathrm{x}_{3}
\end{aligned}
$$

where:

$\mathrm{F}\left(\mathrm{x}_{1}, \mathrm{x}_{3}\right)$ - effectiveness of SME sector enterprise, $\mathrm{x}_{1}$ - "share of orders realized on time" index, $\mathrm{x}_{3}$ - "profitability of assets" index.

The value $F\left(x_{1}, x_{3}\right)$ is a forecast effectiveness value for the enterprise after the implementation of DSS (depending on a current values $\mathrm{x}_{1}$ and $\mathrm{x}_{3}$ ). 
For the exemplary values $\mathrm{x}_{1}=0,8$ and $\mathrm{x}_{3}=0,12$, the effectiveness value for the enterprise after the implementation of DSS S should amount to:

$$
\mathrm{y}_{2}=\mathrm{F}\left(\mathrm{x}_{1}, \mathrm{x}_{3}\right)=43,81
$$

The polynomial decision making model for the enterprise's profit is built of groups of elements, i.e. functioning indexes of sales department of the enterprise, parameters of information system and by means of GMDH algorithm. The decision making model allows to determine the values of control indexes to execute a selection of DSS information system. On the basis of operation effectiveness of the implemented information system (see Table 3, Table 4 and Table 5) there is a possibility of DSS information system selec- tion for the enterprise with regard to the forecast ("the best") profit values or "enterprise effectiveness" after the implementation of DSS. On the basis of the forecast values of these indexes, the management board of the enterprise makes a decision to purchase the DSS.

\section{$4 \quad$ Multi-criteria selection methodology of decision support system}

A building procedure of polynomial decision making model (see Figure 1) is developed in order to develop the multi-criteria selection methodology of decision support system.

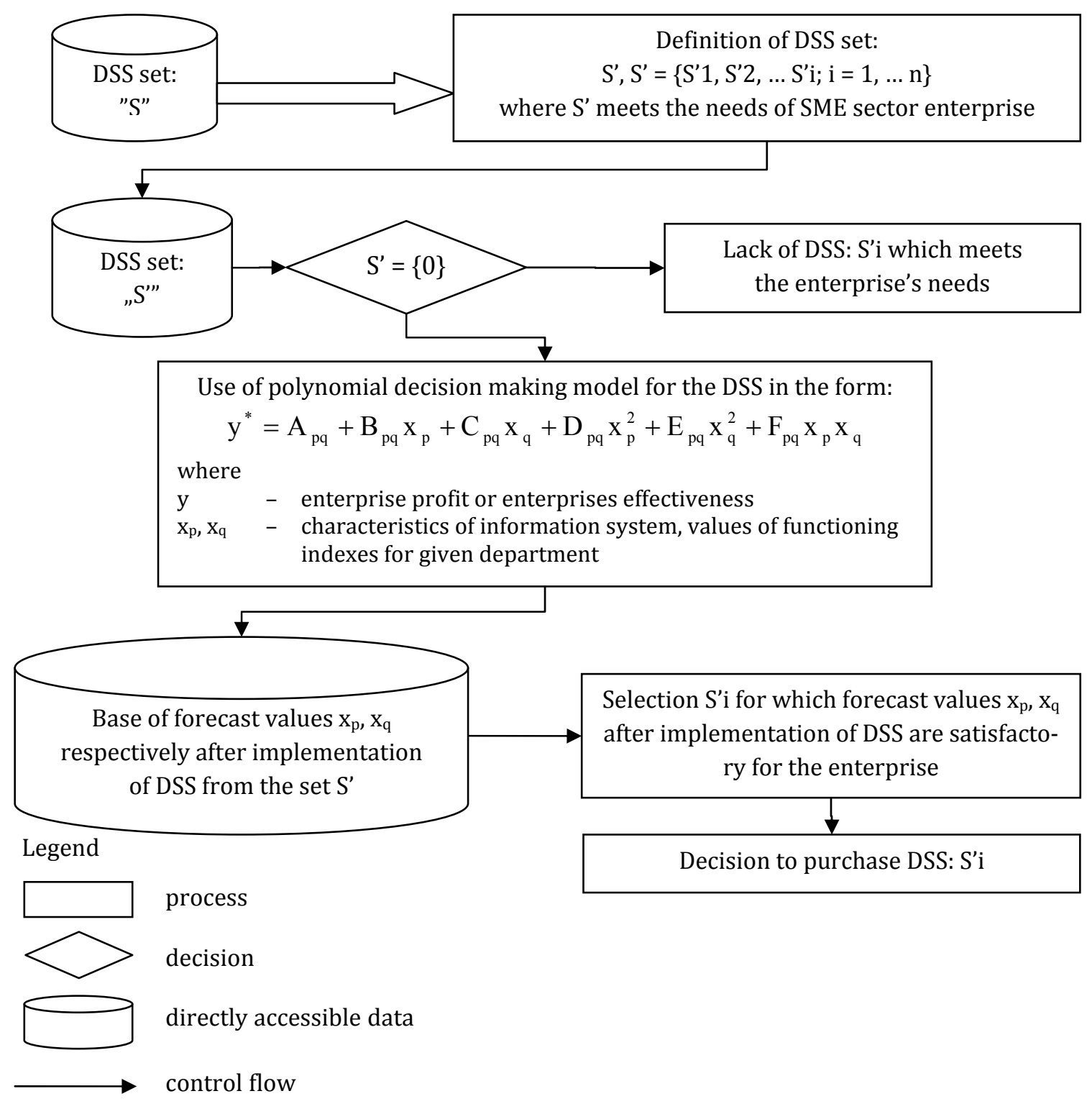

Figure 1. DSS varianting procedure (source: self study) 


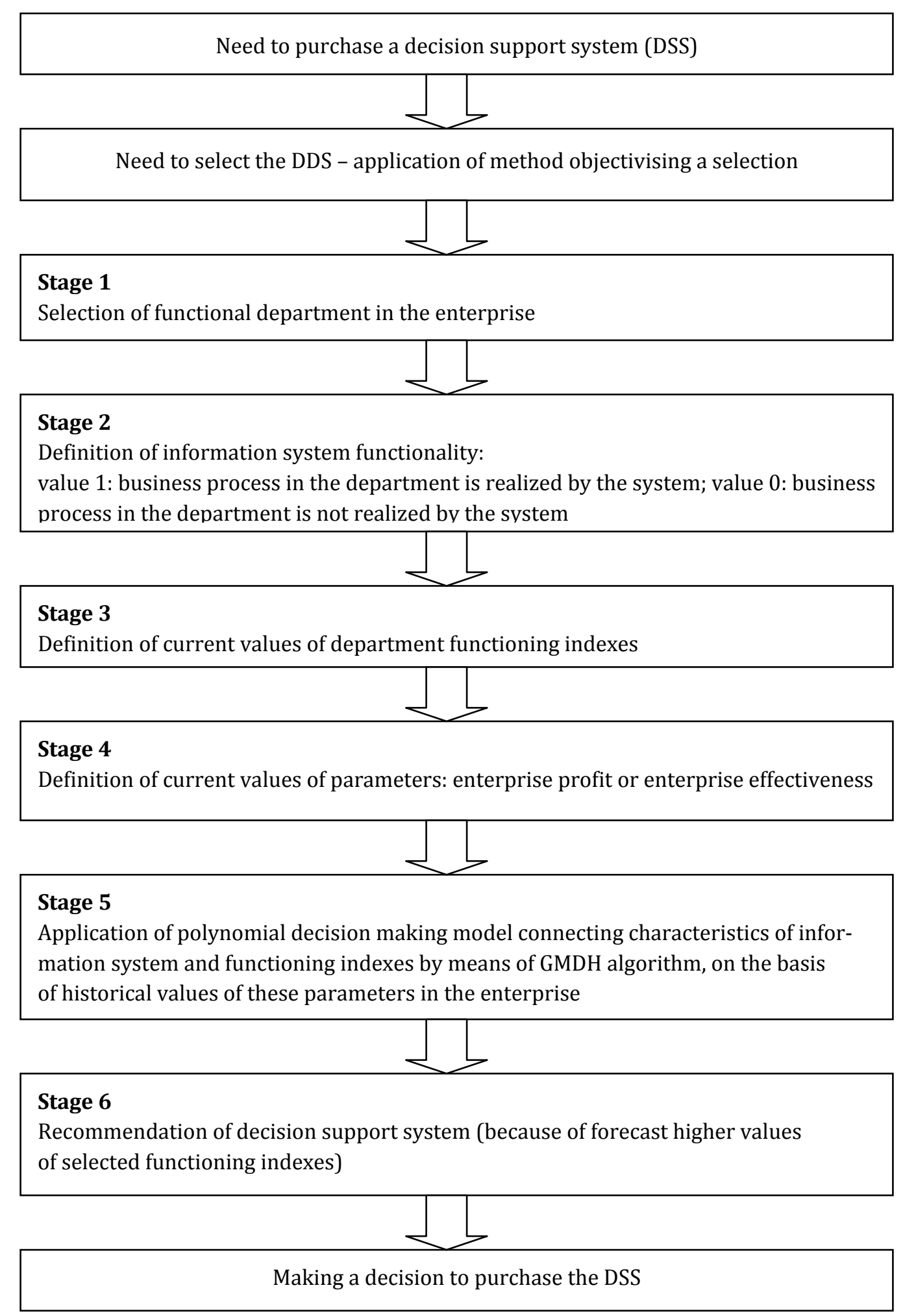

Figure 2. Decision support system selection methodology (source: self study) 
The following realization stages of this procedure are accepted:

- Stage 1 - defining the system's parameters meeting the enterprise's needs by the deliverer of DSS,

- Stage 2 - using a polynomial decision making model respectively for a parameter "profit" or parameter "effectiveness",

- Stage 3 - determining forecast values of selected functioning indexes of a given department in the enterprise after the implementation of DSS,

- Stage 4 - determining a scheme of the enterprise's conduct in a DSS selection process.

The main purpose of this point is to present a multicriteria selection methodology of decision support system on the assumption that an information system is implemented in the enterprise (see Figure 2).

The presented methodology objectivising a selection of decision support system gives additional possibilities to achieve a forecast of values of the enterprise's functioning indexes as a result of DSS implementation. The values of defined indexes in the enterprise, being before a decision to implement the system, are estimated on the basis of polynomial decision making model. A developed forecast allows to make an objective selection of DSS.

There are several possibilities of further work on an undertaken subject. It is possible to modify accepted assumptions. A modification of the assumption related the number of polynomials under consideration seems to be the simplest. It is assumed that as many polynomials go to the next iteration as many columns of matrix $\mathrm{X}$ are there. It is probable that an increase of the number of polynomials going to the next iteration causes an improvement of quality of the final polynomial. The executed tests showed that a partial polynomial formed for the columns $\mathrm{p}, \mathrm{q}$ is different from a polynomial formed for the columns $q, p$. A GMDH algorithm, in order to limit a number of formed polynomials, assumes that only the polynomials for the columns $\mathrm{p}$, $\mathrm{q}$ for which $\mathrm{p}<\mathrm{q}$ are formed. The alteration of this assumption and the formation of polynomials for all pairs $\mathrm{p}, \mathrm{q}$ in every iteration is possible. Apart from the algorithm modification, a work on improvement of input data of the algorithm is possible as well.

There is a number of examples of practical application of GMDH, based on the sets of retrospective data [3]:

- in Great Britain, in 1980-1990, using GMDH, a forecast of inflation changes in the country for the next 10 years was developed (a model of inflation changes achieved by means of GMDH was identical with real values of the inflation in Great Britain in 1990-2000),

- in the United States, in 1990-2000, using GMDH, a forecast of development of main factors of economical growth in the country was developed,

- in the Ukraine, in 1990-2000, using GMDH, a normative forecast of macroeconomic processes for the next 10 years was developed,

- using GMDH, a forecast of changes in Lake Baikal was developed,

- in the United States, in 1990-2000, a GMDH was applied to diagnostics of cancer diseases,

- in the beginning of the 70-ties American enterprise, Adptronics Inc., applied GMDH to the equipment of quality control of materials used in aviation,

- ComputerLand (Wrocław) makes use of GMDH to detect defects of digital and analogue power supply adaptor of electronic circuit,

- a control of exactness of technological track elements is carried out by means of GMDH in the boiler station evaporation station of Lublin sugar refinery (Poland). The researches related to the development in integration of methods (among other things GMDH) and process diagnostics techniques (in particular control valves) in Lublin sugar refinery were carried out within the framework of DAMADICS project ${ }^{6}$.

The above mentioned examples show a wide GMDH application.

\section{Summary}

A development of information technologies provides with more and more new solutions within the scope of decision support systems. The producers of these systems adjust particular areas of their functionalities the needs of enterprises. A growing offer of such systems forces a need to develop a method objectivising their estimation - a method supporting a selection of determined packet ensuring the fulfilment of individual needs of the enterprise.

\footnotetext{
${ }^{6}$ DAMADICS (Development and Application of Methods for Actuator Diagnosis in Industrial Control Systems) - a project realized within the framework of 5. Frame Program, in 20002003 whose coordinator is professor Ronald J. Patton from The University of Hull in Great Britain.
} 


\section{$6 \quad$ References}

[1] Farlow S.J. (ed.) - Self-organizing Methods in Modelling: GMDH-type Algorithms. Marcel Dekker Inc., New York 1984.

[2] Goldberg D.E. - Algorytmy genetyczne i ich zastosowanie. WNT, Warszawa 1995.

[3] http://www.gmdh.net/GMDH_exa.htm, June 2010.

[4] Hunt E.B., Marin, J. \& Stone P.J. - Experiments in induction. Academic Press, New York 1966.

[5] Iwachnienko A.G. - Polynominal theory of complex systems [in] IEEE Trans. Systems, Man and Cybernetics, Vol. SMC-1, No. 4, 1971.

[6] Osowski S. - Sieci neuronowe w ujęciu algorytmicznym. Wydawnictwo Naukowo-Techniczne, Warszawa 1996.
[7] Patalas J., Kłos S., Stryjski R. - Ocena efektywności wdrożeń systemów klasy ERP w SME [in] Komputerowo zintegrowane zarządzanie (ed. R. Knosala). WNT, Warszawa 2005.

[8] Patalas J., Krupa T. - The ERP class system objective assessment method [in] Applied Computer Science, Vol. 1, No. 1, pp. 115-132, 2005.

[9] Shang S., Seddon P. - A comprehensive framework for classyfing the benefits of ERP systems, 2000 [in] Proceedings of AMCIS'2000, Vol. II, 2000, pp. 1005-1014.

[10] Tadeusiewicz R. - Sieci neuronowe. Akademicka Oficyna Wydawnicza RM, Warszawa 1993. 